\title{
Diagnosis and management of glutaric aciduria type I - revised recommendations
}

\author{
Stefan Kölker • Ernst Christensen • James V. Leonard • Cheryl R. Greenberg • \\ Avihu Boneh • Alberto B. Burlina - Alessandro P. Burlina • Marjorie Dixon • \\ Marinus Duran • Angels García Cazorla • Stephen I. Goodman • David M. Koeller • \\ Mårten Kyllerman • Chris Mühlhausen • Edith Müller • Jürgen G. Okun • \\ Bridget Wilcken • Georg F. Hoffmann • Peter Burgard
}

Received: 15 November 2010 /Revised: 19 January 2011 / Accepted: 24 January 2011 /Published online: 23 March 2011

(C) The Author(s) 2011. This article is published with open access at Springerlink.com

\begin{abstract}
Glutaric aciduria type I (synonym, glutaric acidemia type I) is a rare organic aciduria. Untreated patients characteristically develop dystonia during infancy resulting in a high morbidity and mortality. The neuropathological correlate is striatal injury which results from encephalo-
\end{abstract}

Communicated by: Ertan Mayatepek

References to electronic databases: Glutaric aciduria type I: OMIM \# 231670. Glutaryl-CoA dehydrogenase: EC 1.3.99.7.

Competing interest: None declared.

Electronic supplementary material The online version of this article (doi:10.1007/s10545-011-9289-5) contains supplementary material, which is available to authorized users.

S. Kölker $(\varangle) \cdot$ E. Müller · J. G. Okun • G. F. Hoffmann •

P. Burgard

Department of General Pediatrics,

Division of Inborn Metabolic Diseases,

University Children's Hospital,

Im Neuenheimer Feld 430, 69120 Heidelberg, Germany

e-mail: Stefan.Koelker@med.uni-heidelberg.de

E. Christensen

Department of Clinical Genetics, Rigshospitalet,

DK-2100 Copenhagen, Denmark

\section{J. V. Leonard}

Clinical and Molecular Genetics Unit,

UCL Institute of Child Health,

London WC1N 1EH, United Kingdom

\section{R. Greenberg}

Department of Biochemical and Medical Genetics,

Winnipeg Children's Hospital, University of Manitoba,

Winnipeg, MB , R3A 1R9, Canada pathic crises precipitated by infectious diseases, immunizations and surgery during a finite period of brain development, or develops insidiously without clinically apparent crises. Glutaric aciduria type I is caused by inherited deficiency of glutaryl-CoA dehydrogenase which is involved in the catabolic pathways of L-lysine, L-hydroxylysine and Ltryptophan. This defect gives rise to elevated glutaric acid, 3-hydroxyglutaric acid, glutaconic acid, and glutarylcarnitine which can be detected by gas chromatography/mass spectrometry (organic acids) or tandem mass spectrometry (acylcarnitines). Glutaric aciduria type I is included in the panel of diseases that are identified by expanded newborn screening in some countries. It has been shown that in the

A. Boneh

Metabolic Service, Victorian Clinical Genetics Services,

The Murdoch Children's Research Institute,

Royal Children's Hospital Melbourne,

Flemington Road, Parkville 3052, Australia

A. B. Burlina

Metabolic Unit, Department of Pediatrics,

University Hospital of Padova,

35128 Padova, Italy

A. P. Burlina

Neurological Unit, San Bassiano Hospital, 36061 Bassano del Grappa, Italy

M. Dixon

Dietetic Department, Great Ormond Street Hospital for Children, London WC1N 3JH, United Kingdom 
majority of neonatally diagnosed patients striatal injury can be prevented by combined metabolic treatment. Metabolic treatment that includes a low lysine diet, carnitine supplementation and intensified emergency treatment during acute episodes of intercurrent illness should be introduced and monitored by an experienced interdisciplinary team. However, initiation of treatment after the onset of symptoms is generally not effective in preventing permanent damage. Secondary dystonia is often difficult to treat, and the efficacy of available drugs cannot be predicted precisely in individual patients. The major aim of this revision is to re-evaluate the previous diagnostic and therapeutic recommendations for patients with this disease and incorporate new research findings into the guideline.

\section{Abbreviations \\ AA Amino acids \\ C5DC Glutarylcarnitine \\ DBS Dried blood spots \\ GA Glutaric acid \\ GA-I Glutaric aciduria type I}

\section{Duran}

Academic Medical Centre,

Laboratory of Genetic Metabolic Diseases FO-224,

NL-1100 AZ Amsterdam, The Netherlands

\section{A. García Cazorla}

Neurology and Metabolism Department,

Hospital Sant Joan de Déu, Universitat de Barcelona,

Esplugues de Llobregat, 08950 Barcelona, Spain

\section{S. I. Goodman}

Department of Pediatrics,

University of Colorado Health Sciences Center,

Denver, CO 80045, USA

\section{M. Koeller}

Departments of Pediatrics, Molecular and Medical Genetics, Doernbecher Children's Hospital,

Oregon Health and Science University,

Portland, OR 97239, USA

M. Kyllerman

The Queen Silvia Children's Hospital, Gothenburg University, 41685 Göteborg, Sweden

C. Mühlhausen

Department of Pediatrics,

University Medical Center Hamburg-Eppendorf,

Martinistrasse 52, 20246 Hamburg, Germany

B. Wilcken

The Children's Hospital at Westmead, and the Disclipine of Paediatrics, University of Sydney,

Westmead NSW, 2145 Syndey, Australia

$\begin{array}{ll}\text { GCDH } & \text { Glutaryl-CoA dehydrogenase } \\ \text { GCP } & \text { Good clinical practice } \\ \text { GC/MS } & \text { Gas chromatography/mass spectrometry } \\ \text { GDG } & \text { Guideline developmental group } \\ \text { MS/MS } & \text { Tandem mass spectrometry } \\ \text { 3-OH-GA } & \text { 3-hydroxyglutaric acid } \\ \text { PKU } & \text { Phenylketonuria } \\ \text { SIGN } & \text { Scottish Intercollegiate Guidelines Network }\end{array}$

\section{Introduction}

Glutaric aciduria type I (synonym, glutaric acidemia type I) is an autosomal recessive disease caused by inherited deficiency of glutaryl-CoA dehydrogenase (GCDH, EC 1.3.99.7). It has an estimated prevalence of 1 in 100,000 newborns (Lindner et al. 2004). The GCDH gene is localized on chromosome 19p13.2 and encodes a flavin adenine dinucleotide-dependent mitochondrial matrix protein that is involved in the degradative metabolism of L-lysine, Lhydroxylysine and L-tryptophan (Fu et al. 2004; Greenberg et al. 1995). More than 200 disease-causing mutations are known (Goodman et al. 1998; Zschocke et al. 2000). Biochemically, GA-I is characterized by an accumulation of glutaric acid (GA), 3-hydroxyglutaric acid (3-OH-GA), glutaconic acid (less frequently), and glutarylcarnitine (C5DC). These can be detected in body fluids (urine, plasma, CSF) and tissues by gas chromatography/mass spectrometry (GC/MS) or electrospray-ionization tandem mass spectrometry (MS/MS; Baric et al. 1999; Chace et al. 2003). Two biochemically defined subgroups of patients have been described based on urinary metabolite excretion of GA, i.e., low and high excretors (Baric et al. 1999). The low excreting patients have the same risk of developing striatal injury as the high excretors (Christensen et al. 2004; Kölker et al. 2006) and must not be considered to have a "mild" clinical phenotype.

Since the description of two index patients in 1975 (Goodman et al. 1975) more than 500 patients have been reported worldwide. Four genetic isolates with a high carrier frequency (up to 1:10) and over-representation of this disease have been identified, the Amish Community (Morton et al. 1991), Canadian Oji-Cree natives (Haworth et al. 1991), the Irish travellers (Naughten et al. 2004), and the Lumbee in North Carolina (Basinger et al. 2006). Untreated, approximately $90 \%$ of patients will develop neurological disease during a finite period of brain development (age 3-36 months) following an acute encephalopathic crisis often precipitated by gastroenteritis, intercurrent febrile illness, immunization, or surgical intervention (Hoffmann et al. 1991; Kölker et al. 2006). The 
characteristic neurological sequela of these crises is acute bilateral striatal injury and, subsequently, a complex movement disorder. Dystonia is the dominant extrapyramidal symptom, usually superimposed on axial hypotonia (Hoffmann et al. 1991; Kyllerman et al. 1994; Heringer et al. 2010). With aging, there is a tendency for a fixed dystonia and akinetic-rigid parkinsonism to develop (Gitiaux et al. 2008). Morbidity and mortality is high in patients who have had a crisis (Kyllerman et al. 2004; Kölker et al. 2006). In 10-20\% of patients, neurologic disease has been demonstrated in the absence of any documented encephalopathic crisis and has been termed insidious-onset (Busquets et al. 2000; Hoffmann et al. 1996) and late-onset (Bähr et al. 2002; Külkens et al. 2005). Two patients with insidious-onset type were reported in whom striatal injuries had occurred before or shortly after birth, followed by latent periods of several months before disability was apparent (Strauss et al. 2007). This study suggests that catabolism in the postnatal transition period may contribute to the manifestation of neurological impairment.

During the last three decades therapeutic concepts have been established and optimized for GA-I. Dietary treatment in combination with oral supplementation of L-carnitine and riboflavin (less frequently) during maintenance treatment, and an intensified emergency treatment during episodes of intercurrent illness are used for the majority of patients. This treatment strategy has considerably reduced the frequency of acute encephalopathic crises and thus morbidity and mortality in early diagnosed patients (Kölker et al. 2006; Kölker et al. 2007a; Monavari and Naughten 2000; Strauss et al. 2003; Strauss et al. 2007). Indeed a recent study has confirmed the effectiveness of emergency and maintenance therapy (Heringer et al. 2010). Therefore, GA-I is now considered to be a treatable condition. Furthermore, studies in Gcdh-deficient mice, an animal model for GA-I, has provided evidence that low lysine diet and increased glucose intake reduces the accumulation of putatively neurotoxic GA and 3-OH-GA in the brain, and that carnitine supplementation increases the formation of C5DC and the brain, liver and plasma concentrations of free carnitine (Sauer et al. 2010; Zinnanti et al. 2007).

Early clinical diagnosis is hampered by the lack of characteristic or even pathognomonic signs and symptoms before an encephalopathic crisis. Macrocephaly is found in $75 \%$ of patients during infancy (Bjugstad et al. 2000), but is non-specific. Therefore GA-I has been included in the disease panel of newborn screening in some countries. DNA-based mutation analysis is used for the high-risk screening in one cohort of low excretors (Greenberg et al. 2002).

Significant differences still exist in the approaches used to diagnose and manage affected patients, and there is a wide variation in the outcome, particularly in patients diagnosed presymptomatically (Kölker et al. 2006). The major aim of this guideline is to re-assess the common practice and to formulate recommendations for diagnosis and management of GA-I based on the best evidence available.

\section{Methods}

Guideline development

The guideline development process was initiated following the 3rd International Workshop on Glutaryl-CoA Dehydrogenase Deficiency in Heidelberg, Germany (October 2003). Three further meetings were held in Rimini (May 2004), Amsterdam (August 2004), and Prague (May 2005). Working groups were established focusing on the guideline topics. The members of the guideline development group (GDG) performed systematic literature review, drafted the guideline, and discussed it with the GDG members and external consultants. The guideline draft was reviewed by external consultants (J. V. Leonard, M. Dixon, R. Surtees†, M. Kyllerman, B. Wilcken). The final guideline was published in 2007 (Kölker et al. 2007b) and, subsequently, it was revised including new literature and feedback from metabolic experts. The 1 st revision was based on discussions during the 5th guideline meeting in Hamburg (September 2007). The recent 2 nd revision is based on the 6 th guideline meeting in San Diego (September 2009). The GDG consists of Pediatric metabolic specialists and child neurologists (A. Boneh, A. B. Burlina, S. I. Goodman, A. Garcia Cazorla, C. R. Greenberg, G. F. Hoffmann, D. M. Koeller, S. Kölker [chairman], C. Mühlhausen, E. R. Naughten), chemists (E. Christensen, M. Duran, J. G. Okun [secretary]), a psychologist (P. Burgard), specialist metabolic dietitians (E. Müller, M. Dixon), and an adult neurologist (A. P. Burlina).

\section{Systematic literature review}

The evidence base for this guideline was similar to the methodology used by SIGN (Scottish Intercollegiate Guideline Network; URL: http://www.sign.ac.uk). A systematic review of the literature on GA-I was carried out using Medline, Embase, the Cochrane Library, MedLink, and Orphanet. The years covered were 1975-2010. Internet searches were also performed on various websites including international and national societies for inborn errors of metabolism and those of parent groups. The main searches were selected and evaluated by a minimum of two members of the GDG before conclusions were considered as evidence (Suppl. Tables 1-3). 
Prospective follow-up study evaluating the guideline

To evaluate whether the use of the guideline improves the outcome of affected individuals with GA-I, some of the GDG members (S. K., G. F. H., P. B., C. M., E. M.) performed a prospective follow-up study in Germany including 52 patients. This study has confirmed that the use of therapy recommendations (see statements \#7-9 of this guideline) significantly improves the outcome of patients diagnosed by newborn screening (Heringer et al. 2010). It showed for the first time that both basic metabolic treatment (low lysine diet, carnitine supplementation) and emergency treatment were clearly beneficial for patients diagnosed by newborn screening. The beneficial effect of emergency treatment was more pronounced than that of maintenance treatment. Furthermore, this study confirmed that follow-up by a metabolic center is beneficial, highlighting that treatment and follow-up of these patients should be performed by an interdisciplinary team of specialists (see statement \#6).

To the best of our knowledge, none of the recommendations in the previously published guideline (Kölker et al. 2007b) have been proven invalid. However, based on clinical studies published in the interim the level of evidence on which recommendations are based has changed in some areas. To improve the clarity of the text, the wording of some statements has been revised and ageadapted recommendations have been included for metabolic maintenance and emergency treatment. Furthermore, we have removed six good clinical practice (GCP) statements and four low grade recommendations (previous statements $\# 7,9-11,13-16,21$, and 26) reducing the total number of statements from 31 to 21 . This has been made to improve the readability by providing this information in the text only and to focus on statements with defined level of evidence. Five GCP statements with high practical relevance $(\# 1,10,11,17$, and 21) have been left in the revised version.

\section{Diagnostic procedure}

Figure 1 summarizes the diagnostic procedure for GA-I.

\section{Differential diagnoses}

GA-I is defined as inherited deficiency of GCDH confirmed by enzyme analysis and/or demonstration of two diseasecausing mutations. All other signs, symptoms and laboratory abnormalities that are found in affected patients are not pathognomonic so that the diagnosis should be suspected, but is not confirmed. These include macrocephaly, acute enceph- alopathy, basal ganglia injury, white matter disease, movement disorders, subdural and retinal hemorrhage, and isolated elevation of GA, 3-OH-GA, and C5DC in body fluids. Most of these in isolation have a wide differential diagnosis, whereas a combination of two or more abnormalities increases the probability for GA-I.

Statement \#1. The accurate diagnosis of GA-I has important practical implications when devising treatment plans and giving appropriate information to children and their families. The diagnostic work-up should be done by metabolic specialists (GCP).

\section{Newborn and high-risk screening}

Newborn screening disease panel GA-I has been widely considered a disorder for which newborn screening should be offered (Pollitt et al. 1997; Thomason et al. 1998; Watson et al. 2006). It has already been included in the disease panels of expanded newborn screening in some countries.

Major aims Timely diagnosis and start of treatment, i.e., before irreversible neurological symptoms occur, results in a better outcome than start of treatment after the onset of neurological disease (Bijarnia et al. 2008; Boneh et al. 2008; Heringer et al. 2010; Hoffmann et al. 1996; Kölker et al. 2006; Kölker et al. 2007a; Naughten et al. 2004; Strauss et al. 2003; Strauss et al. 2007). The aim of newborn and high-risk screening is to reduce the incidence of neurological disease.

Definitions Population-wide newborn mass screening for GA-I is performed by MS/MS analysis of acylcarnitines in newborn blood spots. High-risk screening for GA-I is performed in neonates with an increased a priori risk.

MS/MS Summarizing results from international screening laboratories the overall prevalence of GA-I is approximately 1 in 100,000 newborns but varies considerably in different countries. The diagnostically relevant metabolite is C5DC in dried blood spots (DBS). In addition, some laboratories are also using ratios to other measured acylcarnitines (Lindner et al. 2006) and others repeat the analysis on another bloodspot from the same DBS as an internal quality control, but this is a matter for individual laboratories and no recommendations are given in this guideline. In comparison to DBS, cord blood testing is of limited value in detecting many inherited metabolic diseases (Walter et al. 2009). However, this has not yet been studied systematically in GA-I.

Cut-off levels A C5DC value above the cut-off is considered positive and requires follow-up. The cut-off level for C5DC has to be set by each laboratory as it will be influenced by many factors. Cut-off levels are typically adjusted with more 
Fig 1 Diagnostic algorithm for glutaric aciduria type I. a,

Newborn screening for GA-I is performed using MS/MS. In low excretor cohorts with known mutations, GCDH gene mutation analysis should be considered as alternative method (dotted line). Note that in these patients treatment should be started after the identification of two disease-causing mutations (*). b, Selective screening should be initiated if the diagnosis of GA-I is suspected clinically or there is a positive family history. Note that a few patients with a low-excreting phenotype may show (intermittently) normal urinary excretion of 3-OH-GA (and GA). If an individual shows normal 3-OH-GA (and GA) concentrations in urine (or other body fluids) but presents with highly suspicious signs and symptoms for GA-I, further diagnostic studies should be considered but the decision should be made based on the individual circumstance $(* *)$. Comment on mutation and enzyme analysis: Since $G C D H$ gene analysis is more broadly available than GCDH enzyme analysis, and the identification of two disease-causing mutations not only confirms the diagnosis but also enables accurate genetic counselling and prenatal diagnosis, we recommend starting with GCDH gene analysis. However, depending on local availability and experience, GCDH enzyme analysis could be performed first

\section{A. Newborn \\ screening}

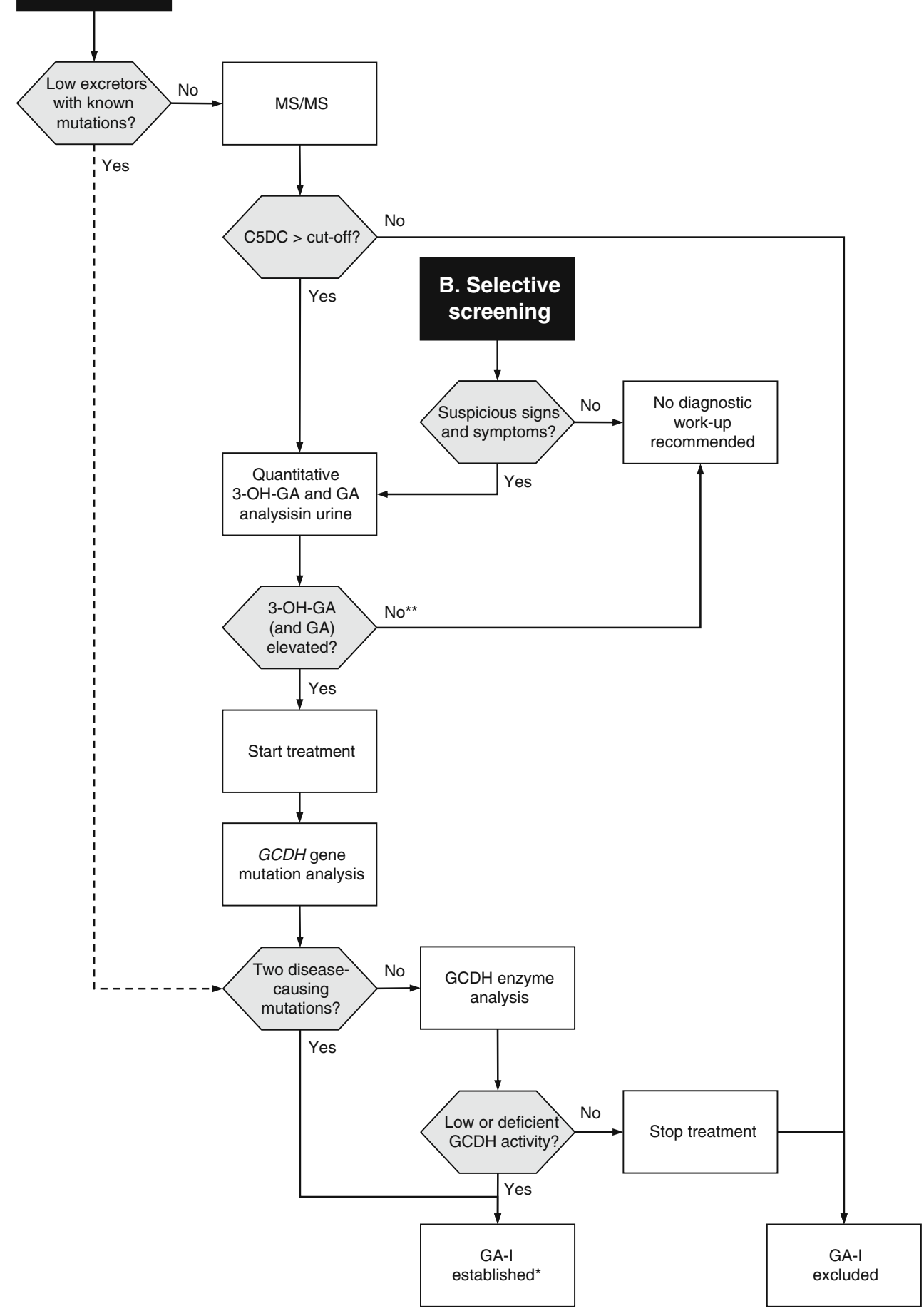

experience of screening, a process that is likely to continue. At present, there is no general recommendation for the establishment and setting of cut-off levels.

Diagnostic pitfalls Not all patients can be diagnosed by this method, as there are patients with a normal or only slightly increased C5DC concentration in DBS. Patients with GA-I have been missed by newborn screening (Heringer et al. 2010; Smith et al. 2001; Wilcken et al. 2003) or by retrospective analysis of the newborn blood spots (Gallagher et al. 2005; Treacy et al. 2003), particularly those with a low excreting phenotype. To circumvent this problem most 
laboratories are now using additional tests for follow-up investigations of initially positive screening results such as analysis of urinary GA and 3-OH-GA. Apparent increases in C5DC have also been demonstrated in medium-chain acyl-CoA dehydrogenase deficiency, most probably because of acylcarnitines of identical mass, such as hydroxydecanoylcarnitine (Napolitano et al. 2004). In patients with multiple acyl-CoA dehydrogenase deficiency, C5DC can also be elevated but is accompanied by increased concentrations of other acylcarnitines. In patients with renal insufficiency due to acquired or congenital renal disease, C5DC can also be increased (Hennermann et al. 2009). Since newborn screening in the child reflects the metabolic state of the mother and infant, newborn screening laboratories should be aware that elevated C5DC concentrations may indicate maternal GA-I (Crombez et al. 2008; Garcia et al. 2008).

Statement \#2. For mass newborn screening for glutaric aciduria type I determination of C5DC in DBS by MS/ MS should be used (grade B, see Suppl. Table 2).

Alternative methods for high-risk population screening Clusters of affected patients from genetic isolates with high carrier frequencies have been identified. The Amish, Irish travellers and Lumbees have a high excretor phenotype (Basinger et al. 2006; Naughten et al. 2004; Strauss et al. 2003), whereas the Oji-Cree natives are low excretors (Greenberg et al. 2002). High-risk screening in the Amish and the Irish travellers was first performed by organic acid analysis but detection of C5DC in DBS is now used. There have been no documented false negatives in the Amish and the Irish travellers populations, whereas false negatives in the Oji-Cree natives were common when MS/MS was used. As a consequence, high-risk screening using DBS and a DNAbased technique specific for the DNA mutation present in this population has been implemented (Greenberg et al. 2002).

Statement \#3. In a cohort with a high disease incidence due to a single common $G C D H$ mutation and a low excretor phenotype, DNA based methods should be considered for newborn screening. The use of MS/MS-based screening in such populations will likely lead to false negative results (grade D).

Confirmation of a positive screening result

A positive MS/MS screening result should be confirmed by one or more alternative techniques, including a sensitive method for quantitative determination of GA and 3-OH-GA in urine or blood such as GC/MS (Al-Dirbashi et al. 2005; Baric et al. 1999; Shigematsu et al. 2005), mutation analysis of the $G C D H$ gene, and/or GCDH enzyme analysis (Christensen 1983; Goodman et al. 1998). A normal urine or blood 3-OH-GA level will make the diagnosis unlikely, whereas an elevated urine or blood level of 3-OH-GA should be followed by mutation analysis and start of treatment. The finding of two known disease-causing mutations will establish the diagnosis. If only one or no known disease-causing mutation or no mutations are found, GCDH activity should be determined. Low enzyme activity will again establish the diagnosis, while a normal activity will exclude it (Fig. 1). Since $G C D H$ gene analysis is more broadly available than GCDH enzyme analysis and since the identification of two disease-causing mutations is also important for prenatal diagnosis and genetic counselling, we recommend starting with $G C D H$ gene analysis. According to local availability and experience, however, GCDH enzyme analysis could be performed first.

Statement \#4. For the confirmation of a positive newborn screening result, a specific diagnostic workup is required, including a quantitative analysis of GA and 3-OH-GA in urine or blood, mutation analysis, and, if feasible, enzyme analysis (grade D).

\section{Selective screening}

If an infant or child presents with clinical signs or symptoms, or neuroradiologic findings (Suppl. Table 4) of GA-I, a diagnostic evaluation should be undertaken regardless of whether the child was previously evaluated in a newborn screening programme. The major disadvantage of relying on clinical suspicion before initiating testing is that there is no single pathognomonic sign or symptom that will reliably identify affected patients before irreversible neurological damage occurs. A few asymptomatic patients have been diagnosed in the course of a diagnostic work-up for macrocephaly (Kölker et al. 2006), but this is a non-specific sign and has a low predictive value. The only effective way to identify patients with a low a priori risk is via newborn screening.

Methods Quantitative organic acid analysis has some advantages for selective screening compared to MS/MS analysis of acylcarnitines in DBS or plasma (higher sensitivity and specificity), particularly in patients with secondary carnitine depletion, and is therefore usually the first line method for selective screening (Baric et al. 1999). False positive test results have been observed (Suppl. Table 5); the separation of 3-OH-GA from 2hydroxyglutaric acid may be cumbersome. The analysis of urinary C5DC is also helpful since it may remain elevated in patients with secondary carnitine depletion, and in low excretors (Tortorelli et al. 2005). Analysis of GCDH enzyme activity in fibroblasts or leukocytes is the 'gold standard' for confirming the diagnosis (Christensen 1983). 
Mutation analysis of the $G C D H$ gene has a sensitivity of 98-99\% (Zschocke et al. 2000). The use of in vivo loading tests using lysine or prolonged fasting tests is not recommended as age-matched controls are usually not available and the tests are potentially harmful.

Statement \#5. In patients with signs and symptoms of glutaric aciduria type I, a specific diagnostic work-up should include quantitative analysis of GA and 3-OHGA in urine or blood, $G C D H$ gene mutation analysis, and/or enzyme analysis (grade D).

\section{Cascade screening}

Cascade screening is the systematic programme of approaching relatives of index patients enabling the identification of asymptomatic patients and of carriers. It is most likely to be valuable in inbred communities and may prevent the manifestation of neurologic disease in patients born before the start of, or missed by, C5DC screening. However, cascade screening may not be necessary once newborn mass screening has been established in a country. Despite the preventive value of the information, relatives may object to cascade screening insisting on their right 'not to know' that they are at risk (de Wert 2005). However, it is important to screen siblings of identified patients.

\section{Metabolic maintenance treatment}

Table 1 summarizes recommended best practice on metabolic maintenance treatment in GA-I based on the clinical experience of the GDG.
Treatment should be started before confirmation of the diagnosis by enzyme and/or mutation analysis where there is strong suspicion of GA-I (Fig. 1). It has been demonstrated recently that implementation of metabolic treatment and regular follow-up by specialized metabolic centers improves the outcome of patients with GA-I (Heringer et al. 2010).

Statement \#6. Metabolic treatment should be implemented by an interdisciplinary team that includes metabolic pediatricians, dietitians, and nurses. Parents and patients should have regular training and written treatment protocols (grade C).

Treatment and outcome

Most patients remain asymptomatic if treatment is started in the newborn period (Bijarnia et al. 2008; Boneh et al. 2008; Heringer et al. 2010; Kölker et al. 2007a; Naughten et al. 2004; Strauss et al. 2003). Dietary treatment in combination with carnitine and emergency treatment has been demonstrated to be effective in preventing neurological disease (Kölker et al. 2007b). Recently the relative efficacy of each single component of this therapy has been evaluated, demonstrating that outcome was best in patients who received all three interventions (low lysine diet, carnitine, and emergency treatment), and that deviations from basic metabolic treatment (low lysine diet, carnitine) resulted in an intermediate outcome. Disregard of emergency treatment recommendations was associated with a poor outcome (Heringer et al. 2010). The results of this study are supported by the highest level of evidence available regarding GA-I (i.e., $2^{++}$), and confirm previous observations suggesting that emergency treatment is the most

Table 1 Metabolic maintenance treatment (protocol proposed by GDG). If normal growth and development are not achieved these recommendations should be modified according to individual needs

\begin{tabular}{|c|c|c|c|c|c|c|}
\hline \multirow[t]{2}{*}{ Treatment } & & \multicolumn{5}{|l|}{ Age } \\
\hline & & $0-6$ months & $7-12$ months & $1-3$ years & $4-6$ years & $>6$ years \\
\hline \multicolumn{7}{|l|}{ 1. Low lysine diet } \\
\hline Lysine (from natural protein) ${ }^{\mathrm{a}}$ & $\mathrm{mg} / \mathrm{kg}$ per day & 100 & 90 & $80-60$ & $60-50$ & \multirow{3}{*}{$\begin{array}{l}\text { Avoid excessive intake of natural } \\
\text { protein; use natural protein with a } \\
\text { low lysine content; according to } \\
\text { 'safe levels' (Suppl. Table 6) }\end{array}$} \\
\hline Amino acid mixtures (protein) ${ }^{\mathrm{b}}$ & $\mathrm{g} / \mathrm{kg}$ per day & $1.3-0.8$ & $1.0-0.8$ & 0.8 & 0.8 & \\
\hline Energy & $\mathrm{kcal} / \mathrm{kg}$ per day & $115-80$ & $95-80$ & $95-80$ & $90-80$ & \\
\hline 2. Micronutrients ${ }^{\mathrm{c}}$ & $\%$ & $\geq 100$ & $\geq 100$ & $\geq 100$ & $\geq 100$ & $\geq 100$ \\
\hline 3. Carnitine & $\mathrm{mg} / \mathrm{kg}$ per day & 100 & 100 & 100 & $100-50$ & $30-50$ \\
\hline
\end{tabular}

${ }^{a}$ The lysine/protein ratio varies considerably in natural food and thus natural protein intake in children on a low lysine diet is dependent on the natural protein source. The natural protein intake is relatively high if patients predominantly use sources of natural protein with a low lysine content.

${ }^{\mathrm{b}}$ Lysine-free, tryptophan-reduced amino acid mixtures should be supplemented with minerals and micronutrients as required to maintain normal levels. Adequate intake of essential amino acids is provided from natural protein and lysine-free, tryptophan-reduced amino acid supplements. The amount of amino acid supplements is adjusted to reach at least the 'safe levels' (Dewey et al. 1996; see also Suppl. Table 6).

${ }^{\mathrm{c}}$ According to international dietary recommendations. 
important component of this treatment strategy (Kölker et al. 2007a, b; Naughten et al. 2004; Strauss et al. 2007). Since striatal injury occurs acutely or insidiously until age 6 years, treatment recommendations for maintenance and emergency treatment are strict for patients at ages 0-6 years and relaxed for patients older than 6 years of life.

In contrast to patients identified presymptomatically, outcome in GA-I is poor when diagnosed after the manifestation of neurological disease (Busquets et al. 2000; Bjugstad et al. 2000; Hoffmann et al. 1996; Kyllerman et al. 2004). The value of metabolic treatment is unclear in patients with severe neurological symptoms, but individual patients may benefit by prevention of progressive neurological deteroriation (Bjugstad et al. 2000; Hoffmann et al. 1996; Kölker et al. 2006; Strauss et al. 2003).

\section{Dietary treatment}

Use of dietary recommendations and individualization of treatment Dietary recommendations outlining the agedependent needs of a growing child have been developed by international organizations (Suppl. Tables 6, 7). They are usually set to the safe level. Note that in Suppl. Table 6 protein recommendations for infants and children may vary significantly between the recommendations due to the use of different reference proteins and the use of average versus safe levels. Standard dietary recommendations can form the basis for dietary treatment in GA-I but due to discrepant and varying requirements for nutrients and energy in symptomatic children they should be adjusted to the individual (Müller and Kölker 2004; Yannicelli et al. 1994). There is still limited practical experience with the use of more recent recommendations such as the report of the joint WHO/FAO/UNU expert consultation (World Health Organization 2007).

Low lysine diet Dietary treatment for GA-I aims to reduce the intake of lysine, the quantitatively most relevant amino acid precursor of neurotoxic GA and 3-OH-GA, while maintaining sufficient intake of essential nutrients and energy substrates. Many metabolic centers limit the total protein intake to reduce lysine intake rather than limiting lysine intake per se. This is often for practical reasons such as the lack of precise or recent data on lysine contents of foods in their country. However, since the lysine content varies considerably in different natural proteins, eg 2-4\% (lysine/protein) in cereals and $9 \%$ (lysine/protein) in fish, the daily lysine intake may be less well controlled by calculation of protein intake rather than lysine intake (Suppl. Table 8). This may also increase the risk of essential amino acid deficiencies, including tryptophan, which is associated with neurological dysfunction such as irritability and sleep irregularity
(Hoffmann et al. 1991). Low lysine diet is often combined with the use of lysine-free, tryptophan-reduced amino acids (AA) supplements. These supplements are given with the aim of preventing malnutrition by providing essential amino acids and (depending on the product) also minerals, trace elements and vitamins. Although in some studies (Busquets et al. 2000; Kölker et al. 2006; Kölker et al. 2007a; Heringer et al. 2010; Naughten et al. 2004) the majority of patients on a low lysine diet also received lysine-free, tryptophan-reduced amino acids supplements, whether a low lysine diet is more effective and safer if it is combined with these supplements has not been systematically studied.

The use of a diet based on lysine intake combined with lysine-free, tryptophan-reduced AA supplements to maintain adequate total protein intake has been associated with the most favorable neurologic outcome and normal growth in some studies (Heringer et al. 2010; Kölker et al. 2006; Kölker et al. 2007a), whereas other studies in smaller cohorts have not found a significant effect of dietary treatment on the outcome (Strauss et al. 2007; Boneh et al. 2008). A possible explanation for this discrepancy is that larger patient groups are required for the delineation of a beneficial effect of dietary treatment from the somewhat stronger effect of emergency treatment. The prescription of dietary treatment should be adjusted to the experience of metabolic centers. For instance, prescribing a total amount of natural protein based on international dietary recommendations in combination with an exchange system (i.e., one exchange is the amount of food which provides $1 \mathrm{~g}$ protein) may be used instead of calculation of lysine intake. This method will reduce overall lysine intake but is likely to be associated with more day to day variability.

Infant feeding Breast feeding has proven benefits for infants but, with the exception of phenylketonuria (PKU), there are few published reports for inherited metabolic diseases (Huner et al. 2005; MacDonald et al. 2006). However, breast feeding in infants with GA-I should be encouraged. It can be performed in analogy to PKU (Francis and Smith 1981) using breastfeeding on demand with special lysine-free and tryptophan-reduced infant formula given prior to breastfeeds thus limiting lysine intake. Although other safe methods for incorporation of breastfeeding into treatment of PKU have been established (van Rijn et al. 2003), they have not been systematically studied in GA-I. Since the amount of lysine in breastmilk is known (86 mg per $100 \mathrm{~mL}$, "Bundeslebensmittelschlüssel II.3"; www.bls.nvs2.de), daily lysine intake can be estimated when breast milk is the only source of natural protein. Bottle feeding can be based on actual lysine intake as the lysine content of infant formula is known. However, 
limiting lysine intake via exclusive use of standard infant formula may increase the risk for nutritional deficiencies.

Statement \#7. A low lysine diet (i.e., reducing lysine intake to a safe requirement) with or without additional administration of lysine-free, tryptophanreduced amino acids supplements should be used for dietary treatment, in particular in asymptomatic patients up to age 6 years (grade C).

Dietary treatment after age 6 years The long-term outcome in patients with GA-I is not well documented. Besides the injury associated with acute encephalopathic crises, there is also evidence of chronic neurologic deterioriation in lateonset and insidious-onset patients with no documented crisis (Bähr et al. 2002; Harting et al. 2009; Külkens et al. 2005). With the exception of single case reports that have suggested a potential benefit to dietary treatment after age 6 years, its efficacy has not been systematically evaluated. However, there is evidence for ongoing extrastriatal neuroradiological changes after age 6 years (Harting et al. 2009), and though the clinical relevance of these changes is unclear, it may be advisable to continue dietary treatment using a less stringent protocol than that used prior to age 6 years.

Children with feeding problems Dystonic children are at increased risk for malnutrition (Müller and Kölker 2004; Yannicelli et al. 1994), mobility and feedings skills are important prognostic parameters (Kölker et al. 2006). Children with feeding problems therefore need skilled metabolic dietetic supervision. They often require tube and overnight feeding and pharmacotherapy or surgery (i.e., fundoplication, gastrostomy, jejunostomy) to maintain adequate nutrition.

Education The efficacy of the low lysine diet critically depends upon adequate provision of information and education of parents, patients and caregivers. It is essential they receive continued support and education.

\section{Pharmacotherapy}

Carnitine supplementation Secondary carnitine depletion in plasma is common in untreated patients (Lipkin et al. 1988; Seccombe et al. 1986), whereas the concomitant intracellular carnitine concentrations are unknown. Conjugation of glutaryl-CoA to form non-toxic C5DC is considered a physiological detoxification, and proposed to replenish the intracellular CoA pool (Seccombe et al. 1986). L-Carnitine supplementation alone or in combination with a low lysine diet is thought to contribute to improved outcome in patients identified during the newborn period (Heringer et al. 2010; Kölker et al. 2007a; Strauss et al. 2003). However, no randomized controlled studies are available (Nasser et al. 2009; Walter 2003). To prevent or reverse secondary carnitine depletion, an initial oral dosage of $100 \mathrm{mg}$ L-carnitine/ $\mathrm{kg}$ per day is commonly used (Kölker et al. 2007a; Strauss et al. 2003). The dosage is then adjusted to maintain the plasma free L-carnitine concentration in the normal range. Usually, oral L-carnitine supplementation can be reduced to $50 \mathrm{mg} / \mathrm{kg}$ per day in children at age 6 years, and further reduced in adolescents and adults. A reduction of L-carnitine can be considered if side effects, such as diarrhoea and fish odor, occur.

Statement \#8. L-Carnitine should be supplemented in patients with glutaric aciduria type I and should be continued lifelong (grade C).

Riboflavin Although an improvement of biochemical parameters has been suggested in single patients (Brandt et al. 1979; Lipkin et al. 1988), there is no firm evidence that riboflavin improves the neurological outcome of this disease (Kölker et al. 2006). Riboflavin responsiveness in GA-I appears to be exceedingly rare (Chalmers et al. 2006). There is no standardized protocol of how to assess riboflavin sensitivity, or means to predict it based on $G C D H$ gene mutation analysis.

Neuroprotective agents There is no firm evidence that administration of other drugs, such as phenobarbitone, $\mathrm{N}$ acetylcysteine, creatine monohydrate, topiramate, glutamate receptor antagonists and antioxidants are beneficial (Greenberg et al. 2002; Kyllerman et al. 1994; Kyllerman et al. 2004; Strauss et al. 2003), though theoretically they may appear to be of value.

\section{Emergency treatment}

Routine treatment does not protect against encephalopathic crises, so it is crucial to use an intensified emergency treatment protocol when the patient is thought to be at risk (Heringer et al. 2010; Monavari and Naughten 2000; Strauss et al. 2007). The decision to institute emergency treatment should be made very freely with a low index of suspicion.

Basic principles of emergency treatment

Emergency treatment follows the basic treatment principles of metabolic diseases of the intoxication type (Dixon and Leonard 1992; Prietsch et al. 2002): (1) the prevention or reversal of a catabolic state by administration of a highenergy intake (plus insulin to control for hyperglycemia if 
required); (2) reduction of GA and 3-OH-GA production by transient reduction or omission of natural protein for $24(-48)$ hours; (3) amplification of physiological detoxification mechanisms and prevention of secondary carnitine depletion by L-carnitine supplementation and (4) maintenance of normal fluid, electrolytes, and $\mathrm{pH}$ status via enteral of IV fluids. Non-adherence to previously described emergency treatment recommendations (Kölker et al. 2007b) has been associated with a high probability of developing striatal injury (Heringer et al. 2010).

\section{Management of emergency treatment}

Preventive care Delayed start of the emergency regimen can have serious consequences. The causes of delay are many and varied; all of these should be identified systematically (Table 2). For example, plans for metabolic management during and after elective surgery should be made ahead in consultation with the surgical team prior to the procedure.
Start of emergency treatment The possibility of a crisis should be suspected during each infectious disease, immunization, or surgical intervention during the vulnerable period (age 0-6 years). In particular, conditions accelerating catabolism, such as repeated vomiting and diarrhoea (with or without fever), and the manifestation of severe neurological symptoms (i.e., hypotonia, irritability, rigor, dystonia, reduced consciousness) should be considered as alarming symptoms. With increasing age, and in particular after age 6 years, the risk of acute neurological insult appears to be much reduced (Bjugstad et al. 2000; Kölker et al. 2006; Strauss et al. 2003). Emergency treatment should aim to start before the onset of alarming neurological symptoms (Heringer et al. 2010; Strauss et al. 2007).
Statement \#9. Emergency treatment should start without delay and should be performed aggressively during febrile illness, surgery and immunization within the vulnerable period for acute encephalopathic crises (up to age 6 years) (grade B).

Table 2 Strategies to prevent delayed start of emergency treatment

Topic $\quad$ Proposed strategies to avoid delay

Education and training of Parents should be informed in detail about the natural history and the particular risks of glutaric aciduria type I, in parents particular the manifestation and neurological sequels of an acute encephalopathic crisis. They should be instructed precisely about the management of maintenance and emergency treatment and this knowledge should be reinforced during regular visits at a metabolic center.

Treatment protocols

Written protocols for maintenance and emergency treatment should be given to all who may be involved (parents, metabolic centers, local hospitals) and kept updated. Parents should also receive an emergency card (preferably laminated) summarizing the key information on glutaric aciduria type I and basic principles of treatment. The telephone number of the responsible metabolic center/physician should be written on the protocol and the emergency card. Parents should take their emergency instructions and supplies of maltodextran and AA supplements when going to hospital.

Supplies

Parents should be advised always to maintain adequate supplies of specialized dietetic products (maltodextran, lysine-free, tryptophan-reduced amino acid mixtures) and drugs required for maintenance treatment and emergency treatment at home.

Local hospital or pediatrician

The closest hospital/pediatrician should be clearly instructed if glutaric aciduria type I has been newly diagnosed in a child. Key information (including written treatment protocols) should be provided to the local hospital/pediatrician without delay and before inpatient emergency treatment might be necessary. Inpatient emergency treatment should be started immediately in the closest hospital if necessary and follows the supervision of the responsible metabolic center which should be contacted without delay.

Holidays

Metabolic specialists/centers in the vicinity of the holiday resort should be informed in writing about the disease and the recent treatment before the start of the holidays. The emergency card and treatment protocols should be translated before the start of the holidarys if necessary.

Infectious diseases

During infectious disease the responsible metabolic center/metabolic specialists should be informed (by parents or local hospitals/pediatricians) without delay to allow supervision of the emergency management. Parents should be instructed to call their doctor and/or metabolic consultant as soon as a temperature of $38.5^{\circ} \mathrm{C}$ is noted and an intercurrent illness is suspected either, an upper respiratory infection, gastrointestinal infection or if increased irritability develops.

Vomiting/diarrhoea Vomiting and diarrhoea is particularly dangerous - even in the absence of fever. Please follow the recommendations for "infectious diseases" (see above).

Surgery

If a surgical intervention is planned, the responsible metabolic center/specialist should be informed before such interventions to discuss the specific risks of affected patients with surgeons and anaesthesiologists, to recommend a protocol for the postsurgical metabolic management and to allow supervision of this period. If possible, the postsurgical metabolic management should be performed in a metabolic center. In general, fasting should be avoided, glucose infusions applied, and carnitine dosage doubled. 
Emergency treatment at home If the body temperature is less than $38.5^{\circ} \mathrm{C}$ and the child is not vomiting, is tolerating the formulae and if there is no alteration in level of consciousness or any other alarming neurological symptoms, a trial treatment period at home of up to 12 hours is recommended. During this time period patients should be reassessed every two hours regarding state of consciousness, fever, and feed tolerance. If parents are adequately trained, maltodextran solutions can be applied via nastrogastric, gastrostomy, or jejunostomy tube to achieve overnight and optimal energy intakes. If body temperature rises above $38.5^{\circ} \mathrm{C}$, antipyretics such as ibuprofen or paracetamol should be administered. If emergency treatment at home is successful and no worrying signs or symptoms occur during this period, maintenance treatment should be reintroduced stepwise during the next $48(-72) \mathrm{h}$. Table 3 summarizes recommended best practice based on the clinical experience of the GDG.

Emergency treatment at hospital If the patient has recurrent vomiting, recurrent diarrhoea, reduced intake of nutrients, spiking temperature or concerning neurological signs, emergency therapy at home is not safe and the patient should be transferred immediately to a metabolic center or the closest hospital (preferably under the guidance of a metabolic center). At hospital the child should be seen immediately, assessed and treatment begun. Table 4 summarizes recommended best practice based on the clinical experience of the GDG.
Emergency treatment after age 6 years Although encephalopathic crises are extremely rare if they occur at all after age 6 years (Bjugstad et al. 2000; Kölker et al. 2006; Strauss et al. 2003), it cannot be concluded that febrile illness, surgery and immunization are completely harmless at this age group.

Statement \#10. Emergency treatment in children after age 6 years should be considered at least during severe illness. It should be performed similarly to that in the age group 0-6 years with adaptation to the individual (GCP).

\section{Management of neurologic complications}

The major neurological complications in GA-I are the manifestation of a complex movement disorder and subdural hemorrhage. Epileptic seizures and arachnoid cysts may also be observed.

\section{Management of movement disorders}

Striatal injury induces a variable clinical picture. Dystonia superimposed on axial hypotonia is usually the dominant extrapyramidal symptom (Hoffmann et al. 1996; Kyllerman et al. 1994). With aging, it tends to evolve from mobile to fixed dystonia and to be associated with akinetic-rigid parkinsonism (Gitiaux et al. 2008). Prevention of fixed dystonia and joint deformities can be done by means of

Table 3 Emergency treatment at home (protocol proposed by GDG)

\begin{tabular}{lllll}
\hline \multirow{2}{*}{ A. Oral carbohydrates } & a & & & \\
\cline { 2 - 5 } Agears) & $\%$ & $\mathrm{kcal} / 100 \mathrm{~mL}$ & $\mathrm{KJ} / 100 \mathrm{~mL}$ & Volume (mL) per day orally \\
\hline Up to 0.5 & 10 & 40 & 167 & min. $150 / \mathrm{kg}$ \\
$0.5-1$ & 12 & 48 & 202 & $120 / \mathrm{kg}$ \\
$1-2$ & 15 & 60 & 250 & $100 / \mathrm{kg}$ \\
$2-6$ & 20 & 80 & 334 & $1200-1500$ \\
$6-10$ & 20 & 80 & 334 & $1500-2000$ \\
$>10$ & 25 & 100 & 418 & $2000-2500$
\end{tabular}

B. Protein intake

Natural protein

AA mixtures ${ }^{\mathrm{b}}$

Stop for 24 to a maximum of 48 hours, then reintroduce and increase stepwise until the amount of maintenance treatment is reached within $48(-72)$ hours. Prolongation of inadequately low protein intake increases the risk of protein catabolism.

C. Pharmacotherapy

L-Carnitine Double carnitine intake: eg $200 \mathrm{mg} / \mathrm{kg}$ per day p.o. in infants

Antipyretics If body temperature raises above $38.5^{\circ} \mathrm{C}(101 \mathrm{~F})$, antipyretics, such as ibuprofen or paracetamol (each $10-15 \mathrm{mg} / \mathrm{kg}$ per single dose, 3-4 doses daily, maximum daily dose $60 \mathrm{mg} / \mathrm{kg}$ body weight) should be administered.

\footnotetext{
${ }^{\text {a }}$ Solutions should be administered every 2 hours day and night.

${ }^{\mathrm{b}}$ If neonates and infants also receive a lysine-free, tryptophan-reduced amino acid supplement, this can be continued but should be fortified by maltodextran. Patients should be re-assessed every 2 hours.
} 
Table 4 Emergency treatment in hospital (protocol proposed by GDG)

A. Intravenous infusions

\begin{tabular}{|c|c|c|}
\hline \multirow[t]{6}{*}{ Glucose } & Age (years) & Glucose $(\mathrm{g} / \mathrm{kg}$ per day IV) \\
\hline & $0-1$ & $(12-) 15$ \\
\hline & $1-3$ & $(10-) 12$ \\
\hline & $3-6$ & $(8-) 10$ \\
\hline & $6-10$ & $(6-) 8$ \\
\hline & $>10$ & $3-6$ \\
\hline Insulin & \multicolumn{2}{|c|}{$\begin{array}{l}\text { If persistent hyperglycemia }>150 \mathrm{mg} / \mathrm{dL}(>8 \mathrm{mmol} / \mathrm{L}) \text { and/or glucosuria occurs, start with } 0.05 \mathrm{IE} \text { insulin } / \mathrm{kg} \text { per } \mathrm{h} \text { IV and } \\
\text { adjust the infusion rate according to serum glucose }\end{array}$} \\
\hline \multicolumn{3}{|l|}{ B. Protein intake } \\
\hline Natural protein & \multicolumn{2}{|c|}{$\begin{array}{l}\text { Stop for } 24 \text { to a maximum of } 48 \text { hours, then reintroduce and increase stepwise until the amount of maintenance treatment is } \\
\text { reached within } 48(-72) \text { hours. Prolongation of inadequately low protein intake increases the risk of protein catabolism. }\end{array}$} \\
\hline AA mixtures ${ }^{\mathrm{a}}$ & \multicolumn{2}{|c|}{$\begin{array}{l}\text { If tolerated, lysine-free and tryptophan-reduced AA mixtures should be administered orally or by nasogastric tube } \\
\text { according to maintenance therapy (see also Table 1). }\end{array}$} \\
\hline \multicolumn{3}{|l|}{ C. Pharmacotherapy } \\
\hline L-Carnitine & \multicolumn{2}{|c|}{ (50-) $100(-200) \mathrm{mg} / \mathrm{kg}$ per day i.v. - adjusted to oral dosage (see Table 1) } \\
\hline Antipyretics & \multicolumn{2}{|c|}{$\begin{array}{l}\text { If body temperature rises above } 38.5^{\circ} \mathrm{C}(101 \mathrm{~F}) \text {, antipyretics, such as ibuprofen or paracetamol (each } 10-15 \mathrm{mg} / \mathrm{kg} \text { per } \\
\text { single dose, } 3-4 \text { doses daily, maximum daily dose } 60 \mathrm{mg} / \mathrm{kg} \text { body weight) should be administered. }\end{array}$} \\
\hline Sodium bicarbonate & \multicolumn{2}{|c|}{ If acidosis; alkalination of urine also facilitates urinary excretion of organic acids } \\
\hline \multicolumn{3}{|l|}{ D. Monitoring } \\
\hline Blood & \multicolumn{2}{|c|}{$\begin{array}{l}\text { Glucose, blood gases, electrolytes, calcium, phosphate, complete blood cell count, creatinine, urea nitrogen, C-reactive } \\
\text { protein, amino acids }{ }^{\mathrm{b}} \text {, carnitine, blood culture (if applicable), amylase/lipase }{ }^{\mathrm{c}} \text {, creatine kinase }{ }^{\mathrm{c}} \text {. }\end{array}$} \\
\hline Urine & \multicolumn{2}{|c|}{ Ketone bodies, $\mathrm{pH}$} \\
\hline Vital signs & \multicolumn{2}{|c|}{$\begin{array}{l}\text { Heart rate, blood pressure, temperature, diuresis; Glasgow Coma Scale if reduced consciousness; assessment for } \\
\text { neurological signs (hypotonia, irritability, rigor, dystonia) }\end{array}$} \\
\hline
\end{tabular}

${ }^{\text {a }}$ Lysine-free, tryptophan-reduced amino acid mixtures should be supplemented with minerals and micronutrients.

${ }^{\mathrm{b}}$ During the recovery phase.

${ }^{\mathrm{c}}$ In severe illness to detect pancreatitis (amylase/lipase) or rhabdomyolysis (creatine kinase).

physical and occupational therapy as well as with pharmacological and surgical treatments.

Statement \#11. In all patients with GA-I, expert neurological evaluation should be performed by a neuropediatrician and/or later on by a neurologist to identify clearly the kind and severity of movement disorder. In addition, dietitians, physicotherapists, occupational therapists, orthopedists, seating and speech specialists and providers of communication aids, should be consulted to provide multi-disciplinary support for children with movement disorders (GCP).

\section{Dystonia rating scales}

Objective assessment of the complex movement disorder in symptomatic patients is important to evaluate the efficacy of treatment and to adjust the dosage of medications. One study (Heringer et al. 2010) however has identified limitations in the use of the Barry-Albright dystonia rating scale (Monbaliu et al. 2010; Barry et al. 1999) since it likely underestimated the severity of the movement disorder in infants and young children.

\section{Drug therapy}

Movement disorders in GA-I are very difficult to treat, and many of the drugs used have not been studied systematically (Burlina et al. 2004). Previous studies have shown that baclofen and benzodiazepines are benefical in the majority of symptomatic patients and are recommended for first-line treatment.

Baclofen Baclofen is generally used for symptomatic treatment of spasticity and also for the long-term treatment of dystonia in GA-I. Together with diazepam it is the most widely used and efficacious drug in GA-I (Hoffmann et al. 1996) and with beneficial effects in 85\% of symptomatic patients (Kyllerman et al. 1994). Oral baclofen should be used in dosages according to general recommendations. Intrathecal baclofen administration has been used with success in a few children with severe 
dystonia (Kyllerman et al. 2004), and reduces the risk of over-sedation.

Benzodiazepines Diazepam (positive effect in more than $90 \%$ of symptomatic patients) and clonazepam have been successfully used in treating dystonia (Hoffmann et al. 1996; Kyllerman et al. 1994; Kyllerman et al. 2004). Dosages should be administered according to general recommendations. In patients in whom the severity of symptoms is highly variable the dosage can be adjusted daily within a given range. Intermittent treatment may be required to prevent tachyphylaxis.

If patients do not benefit from treatment with baclofen and/ or benzodiazepines or adverse effects occur, anticholinergic drugs should be considered as second line medication.

Anticholinergic drugs Trihexyphenidyl can be effective in treating dystonic symptoms but there are few reports on its use in GA-I (Burlina et al. 2004). In children, trihexiphenidyl has been mainly used as a symptomatic treatment for dystonic cerebral palsy. Although the response to trihexiphenidyl treatment seems best in adolescents and adults, it may also be safe and effective in children if sufficient time is given to respond and the dosage is increased slowly. However, secondary effects are common, and it may worsen symptoms in patients with hyperkinetic forms of dystonia, as seen in GA-I (Rice and Waugh 2009; Sanger et al. 2007). Adverse effects such as blurred vision and dry mouth are usually temporary. Memory deficit and confusion usually persist and require a reduction of the dosage. Periodic ocular tonometry is recommended for adult patients.

Botulinum toxin Botulinum toxin type A may be useful to prevent hip dislocation and disabling limb dystonia (Burlina et al. 2004). Some patients may develop immunity against the toxin, precluding further therapy; therefore, botulinum toxin is usually administered every three to six months to minimize the formation of antibodies against the toxin.

Drugs for the movement disorder of no proven benefit or with adverse effects Some antiepileptic drugs have been used in the past (Hoffmann et al. 1996; Kyllerman et al. 1994; Kyllerman et al. 2004; Yannicelli et al. 1994): Vigabatrin and valproate had little effect (i.e., 10-25\% symptomatic patients showed a therapeutic benefit). Vigabatrin has putatively severe adverse effects (peripheral visual field defects). Valproate effectively may promote disturbances in the mitochondrial acetyl-CoA/ CoA ratio. Therefore, valproate and vigabatrin should not be used for the treatment of movement disorder in GA-I. Carbamazepine was always unequivocally ineffective. There is no improvement of the extrapyramidal syndrome with $L$ $D O P A$. In a few patients, amantadine was used but there was no improvement in dystonic movement disorder.
Statement \#12. Baclofen and benzodiazepines as monotherapy or in combination should be used as first line drug treatment for focal and generalized dystonia. Intrathecal baclofen should be considered as additional therapy for generalized dystonia and spasticity. Trihexyphenidyl should be considered as second line treatment for dystonia, particularly in adolescents and adults. Botulinum toxin A should be considered as additional therapy for severe focal dystonia (grade D).

\section{Neurosurgery}

Stereotactic surgery (pallidotomy) for severe generalized dystonia has been reported for three patients. The results reported in two patients were unsatisfactory (Strauss et al. 2003), whereas short-term improvement in dystonic symptoms were described in one (Rakocevic et al. 2004). The results of deep brain stimulation of the globus pallidus internus has not yet been reported in patients with dystonia due to GA-I.

Antiepileptic therapy

Epilepsy is not a major symptom in GA-I, whereas single seizures may be observed during an acute encephalopathic crisis (Greenberg et al. 2002; Kölker et al. 2006; Kyllerman et al. 2004; Strauss et al. 2003). In one child, however, epileptic seizures were the sole presenting feature (McClelland et al. 2009), but dystonic movements may be mistaken as seizures (Cerisola et al. 2009). No study has compared the relative efficacy of antiepileptic agents in GA-I. However, as mentioned before valproate should not be used because of potential effects on mitochondrial function.

Statement \#13. Diagnosis, choice of antiepileptic drug therapy and management of seizures in GA-I should follow existing guidelines - except for the use of valproate which should be avoided in this condition. The diagnosis of epilepsy and choice of antiepileptic drugs should be made by a pediatric neurologist or pediatrician with expertise in childhood epilepsy. In adulthood, patients with epilepsy should be followed and antiepileptic therapy should be monitored by an adult neurologist (GCP).

Subdural haemorrhage and arachnoid cysts

Diagnosis Subdural haemorrhage may occur at any age in GA-I but peaks during the age of maximal extent of macrocephaly, i.e., late infancy (Brismar and Ozand 1995; Köhler and Hoffmann 1998; Woelfle et al. 1996). Minor 
head traumas with disruption of elongated bridging veins have been suggested as underlying mechanisms. The exact frequency of subdural bleeding is unknown, since affected patients may remain asymptomatic. Subdural haemorrhage in GA-I may be mistaken with shaken baby syndrome and vice versa (Hartley et al. 2000; Morris et al. 1999). Bitemporal arachnoid cysts have been described in some affected patients and should result in a high suspicion for GA-I (Hald et al. 1991; Jamjoom et al. 1995; Lücherath et al. 2000; Martinez-Lage et al. 1994), whereas unilateral arachnoid cysts are a rare occurence in this disease.

Statement \#14. Children with subdural haemorrhage and/or bitemporal arachnoid cysts should be investigated for glutaric aciduria type I, in particular if occuring in combination with macrocephaly and/or a movement disorder (grade D).

Statement \#15. Glutaric aciduria type I should be excluded in children with suspected shaken baby syndrome using the recommendations for selective screening (see also statement \#5, Fig. 1) (grade D).

Neurosurgery Neurosurgical interventions have been performed in a small number of affected patients with arachnoid cysts and subdural haemorrhage (Hald et al. 1991; Lütcherath et al. 2000; Martinez-Lage et al. 1994; Woelfle et al. 1996). The majority of these patients had a poor neurological outcome or sometimes with significant worsening of the neurological symptoms in the context of the neurosurgical intervention. In particular, neurosurgical interventions in undiagnosed patients who do not receive specific metabolic treatment neurosurgical interventions can precipitate an encephalopathic crisis. Subdural haemorrhage may regress without neurosurgical intervention.

Statement\#16. Neurosurgical intervention for arachnoid cysts and subdural haemorrhages in affected patients should be undertaken very cautiously in close consultation with the pediatric neurosurgeon (grade D).

The metabolic management during and after any surgical interventions should be based on recommendations for metabolic treatment and should be supervised by a metabolic specialist (see also statements \#6-10).

\section{Monitoring therapy}

Investigative procedures

\section{General aims}

The aim of regular therapy monitoring is to assess the efficacy of treatment and to identify complications or side effects. In children, it should also include an evaluation of psychomotor development and growth. In general, monitoring should include those tests that influence therapeutic decisions and should be preventive in its overall approach. However at present, there is no reliable marker that predicts the outcome of GA-I.

\section{Clinical monitoring}

Clinical monitoring should be frequent, and consist of a wide variety of investigations, including general pediatric parameters (e.g., anthropometrics, developmental milestones), neurological assessment, and specific psychological tests. Although overall average cognitive outcomes may be normal, subtle deficits, mainly in speech development and fine motor function, may be observed in individual patients (Beauchamp et al. 2009; Harting et al. 2009). Expertise from general pediatricians, metabolic specialists, and dietitians from metabolic centers should be included into the evaluation of patients in an integrative way. In addition, consultations from other specialties (e.g., child neurologists, psychologists, physiotherapists) should be considered as necessary.

Statement \#17. Therapy should be accompanied by regular professional monitoring. Monitoring should be intensified at any age if there are new complications (disease- or therapy-related) or non-adherence to treatment $(\mathrm{GCP})$.

\section{Routine biochemical monitoring}

Table 5 summarizes recommended best practice based on the clinical experience of the GDG on routine laboratory monitoring in GA-I. At present, there is no reliable biochemical marker that is useful for the monitoring of maintenance treatment in GA-I and there is considerable variation in expert opinion (Mühlhausen et al. 2004).

Organic acids A decrease in the urinary concentrations of GA and 3-OH-GA has been demonstrated in high excretors following dietary treatment (Hoffmann et al. 1991; Hoffmann et al. 1996; Strauss et al. 2003), whereas this biochemical response is usually not found in the urine of low excretors (Greenberg et al. 2002). At present, there is no evidence that urinary concentrations of GA and 3-OH-GA correlate with the long-term clinical outcome (Christensen et al. 2004; Kölker et al. 2006).

Statement \#18. Urine analysis of GA and 3-OH-GA is not informative for therapy monitoring (grade D).

Amino acids Analysis of all essential amino acids in plasma is useful to ensure that nutrition is not being 
Table 5 Routine biochemical monitoring in glutaric aciduria type I (basic schedule proposed by GDG)

\begin{tabular}{|c|c|c|c|c|}
\hline \multirow[t]{2}{*}{ Parameter } & \multirow[t]{2}{*}{ Rationale } & \multicolumn{3}{|l|}{ Frequency at age } \\
\hline & & $0-2$ years & $2-6$ years & $>6$ years \\
\hline Amino acids (plasma) & General nutritional status & Every $1-2$ months & Every 3 months & Every $6-12$ months \\
\hline Tryptophan (plasma; HPLC) & Tryptophan depletion & \multicolumn{3}{|c|}{$\begin{array}{l}\text { In children with feeding problems; or if clinical presentation } \\
\text { suggests tryptophan depletion; or if amino acid supplement } \\
\text { do not contain tryptophan. }\end{array}$} \\
\hline Carnitine (plasma or serum) & $\begin{array}{l}\text { Avoid depletion, check for } \\
\text { non-adherence }\end{array}$ & Every $1-2$ months & Every 3 months & Every 6-12 months \\
\hline Complete blood cell count, ferritin & $\begin{array}{l}\text { Routine surveillance, avoid depletion } \\
\text { of iron, folate, or cobalamin }\end{array}$ & Every 6 months & Every 6 months & Every 6-12 months \\
\hline Albumin & General nutritional status & \multicolumn{3}{|c|}{$\begin{array}{l}\text { If concerns exist about the nutritional status and in children } \\
\text { with feeding problems }\end{array}$} \\
\hline Calcium, phosphate, alkaline phosphatase & Bone status ${ }^{\mathrm{a}}$, check for compliance & Every 3 months & Every 6 months & Every 12 months \\
\hline Transaminases & Routine surveillance & Every 3 months & Every 6 months & Every 12 months \\
\hline
\end{tabular}

a If inadequate bone mineralization is suggested, additional tests are required (e.g., vitamin D status, parathyroid hormone, radiological investigations for bone age and density).

compromised in patients receiving dietary treatment and in children with feeding problems (Müller and Kölker 2004; Yannicelli et al. 1994). Tryptophan should be assayed by specific HPLC analysis (or MS/MS analysis) as conventional amino acid analysis is not satisfactory (Krstulovic et al. 1977; Laich et al. 2002).

Statement \#19. Amino acids in plasma (ideally 3-4 h postprandially) should be monitored during dietary treatment (grade D).

Carnitine status L-Carnitine supplementation prevents secondary depletion of free carnitine and is thought to contribute to improved outcome (Heringer et al. 2010; Kölker et al. 2006; Seccombe et al. 1986). Carnitine status in plasma can be assessed using HPLC or MS/MS analysis, and gives valuable information on compliance. MS/MS analysis in dried blood spots is also useful to detect secondary carnitine depletion, although less accurately than plasma analysis.

Statement \#20. Carnitine status in plasma should be monitored in all patients to detect secondary carnitine depletion (grade D).

Acylcarnitine profile Assessment of $\mathrm{C} 5 \mathrm{DC}$ and other acylcarnitines in dried blood spots is of little value in regular biochemical monitoring. C5DC will increase markedly with the start of L-carnitine supplementation.

Additional biochemical monitoring Analysis of other parameters, such as complete blood cell count, albumin, calcium, phosphate, vitamin D status, ferritin, and serum transaminases may be helpful for routine surveillance (Yannicelli et al. 1994).

\section{Biochemical monitoring during acute illness}

Vomiting, diarrhoea and reduced intake of nutrients and fluids increase the risk of dehydration, electrolyte abnormalities, acidosis, and subsequently acute encephalopathic crises (Bjugstad et al. 2000; Hoffmann et al. 1996; Kölker et al. 2006; Kyllerman et al. 2004; Strauss et al. 2003). Imbalances in the metabolic state, hydration and serum electrolytes, and complications should be identified on admission and emergency treatment adjusted accordingly.

\section{Neuroradiological monitoring}

Cranial MRI in affected patients often demonstrates a characteristic pattern of gray and white matter changes and abnormalities of CSF spaces that should prompt a high suspicion for the diagnosis of GA-I (Suppl. Table 4). However, striatal and extrastriatal MR abnormalities may be highly variable and may progress in a different way and with discrepant velocity (Harting et al. 2009). MRI studies, in particular those using echo-planar imaging spin-echo or apparent diffusion coefficient maps, detect striatal lesions earlier and more reliably than CT scans (Brismar and Ozand 1995; Desai et al. 2003; Elster 2004; Neumaier-Probst et al. 2004; Oguz et al. 2005; Strauss et al. 2007; Twomey et al. 2003). Some of these neuroradiological changes can also be detected by ultrasound (Forstner et al. 1999), even already during the last trimester of pregnancy (Lin et al. 2002; Mellerio et al. 
2008). The benefit of serial MRI investigations is unclear and is not considered essential for regular monitoring. As long as the fontanelle is open, cranial ultrasound can be used instead (but may miss hygromas).

Statement \#21. Neuroradiologic investigations should be performed in case of neurologic deteroriation but are not generally recommended for regular follow-up monitoring (GCP).

Although many questions remain regarding the pathogenesis and treatment of GA-I, much has been learned since publication of the initial version of this guideline. Basic and clinical research, as well as the diligent recording of the natural history of the disease in many patients, has led to improvements in patient outcomes. These advances in our knowledge and the quality of evidence regarding treatment of GA-I have been incorporated into these revised guidelines. However, in spite of recent advances, future studies will be required to evaluate long-term outcome, better characterize atypical patients, and develop reliable diagnostic algorithms for patients with a low excretor phenotype. Further evidence regarding dietary management and therapy monitoring is also needed. The results of these and other studies will increase the level of evidence of future guidelines, which in the long-term we hope will improve the outcome of all patients with GA-I.

Acknowledgements We thank Eileen R. Naughten for her valuable contribution to the guideline development.

Details of funding This publication arises from the project "EIMD" (to S. Kölker, G. F. Hoffmann, E. Christensen, A. B. Burlina and A. Garcia Cazorla) which has received funding from the European Union, in the framework of the Health Programme. Guideline development for glutaric aciduria type I (GA-I) has also been supported by the German Federal Ministry of Education and Science (BMBF \# 01GM0305; to S. Kölker and G. F. Hoffmann) and the "Kindness for Kids" Foundation, Munich, Germany (to S. Kölker and G. F. Hoffmann). Milupa Metabolics, SHS International, Applied Nutrition, Nutricia, and Vitaflo have sponsored the guidelines meetings. The authors confirm independence from the sponsors; the content of the article has not been influenced by the sponsors.

Disclaimer This guideline is not intended to serve as a standard of care. Standards of care are determined on the basis of all clinical data available for an individual case and are subject to change as scientific knowledge and technology advance and patterns of care evolve. Adherence to guideline recommendations will not ensure the correct diagnosis and satisfactory outcome in every case, nor should they be construed as including all proper methods of diagnostic work-up and care, or excluding other acceptable methods aimed at the same results. The ultimate judgement must be made by the appropriate healthcare professional(s) responsible for clinical decisions regarding a particular clinical procedure or treatment plan. The judgement should only be arrived at following discussions of the options with the patient and their family, covering the diagnostic and treatment choices available.
Open Access This article is distributed under the terms of the Creative Commons Attribution Noncommercial License which permits any noncommercial use, distribution, and reproduction in any medium, provided the original author(s) and source are credited.

\section{References}

Al-Dirbashi OY, Jacob M, Al-Amoudi M, Al-Odaib A, Al-Kahtani, El-Badaoui F, Rashed MS (2005) Quantification of glutaric and 3hydroxyglutaric acids in urine of glutaric acidemia type I patients by HPLC with intramolecular excimer-forming fluorescence derivatization. Clin Chim Acta 359:179-188

Bähr O, Mader I, Zschocke J, Dichgans J, Schulz JB (2002) Adult onset glutaric aciduria type I presenting with leukoencephalopathy. Neurology 59:1802-1804

Baric I, Wagner L, Feyh P, Liesert M, Buckel W, Hoffmann GF (1999) Sensitivity of free and total glutaric and 3-hydroxyglutaric acid measurement by stable isotope dilution assays for the diagnosis of glutaric aciduria type I. J Inherit Metab Dis 22:867-882

Barry MJ, VanSwearingen JM, Albright AL (1999) Reliability and responsiveness of the Barry-Albright Dystonia Scale. Dev Med Child Neurol 41:404-411

Basinger AA, Booker JK, Frazier DM, Koeberl DD, Sullivan JA, Muenzer J (2006) Glutaric academia type 1 in patients of Lumbee heritage from North Carolina. Mol Genet Metab 88:90-92

Beauchamp MH, Boneh A, Anderson V (2009) Cognitive, behavioural and adaptive profiles of children with glutaric aciduria type I detected through newborn screening. J Inherit Metab Dis. doi:10.1007/s10545-009-1167-z

Bijarnia S, Wiley V, Carpenter K, Christodoulou J, Ellaway CJ, Wilcken B (2008) Glutaric aciduria type I: out come following detection by newborn screening. J Inherit Metab Dis 31:503507

Bjugstad KB, Goodman SI, Freed CR (2000) Age at symptom onset predicts severity of motor impairment and clinical onset of glutaric aciduria type I. J Pediatr 137:681-686

Boneh A, Beauchamp M, Humphrey M, Watkins J, Peters H, Yaplito-Lee J (2008) Newborn screening for glutaric aciduria type I in Victoria: treatment and outcome. Mol Genet Metab 94:287-291

Brandt NJ, Gregersen N, Christensen E, Gron ICH, Rasmussen K (1979) Treatment of glutaryl-CoA dehydrogenase deficiency (glutaric aciduria). J Pediatr 94:669-673

Brismar J, Ozand PT (1995) CT and MR of the brain in glutaric aciemia type I: a review of 59 published cases and a report of 5 new patients. Am J Neuroradiol 16:675-683

Burlina AP, Zara G, Hoffmann GF, Zschocke J, Burlina AB (2004) Management of movement disorders in glutaryl-CoA dehydrogenase deficiency: anticholinergic drugs and botulinum toxin as additional therapeutic options. J Inherit Metab Dis 27:911-915

Busquets C, Merinero B, Christensen E et al. (2000) Glutaryl-CoA dehydrogenase deficiency in Spain: evidence of two groups of patients, genetically and biochemically distinct. Pediatr Res 48:315-322

Cerisola A, Campistol J, Pérez-Duenas B et al. (2009) Seizures versus dystonia in encephalopathic crisis of glutaric aciduria type I. Pediatr Neurol 40:426-431

Chace DH, Kalas TA, Naylor EW (2003) Use of tandem mass spectrometry for multianalyte screening of dried blood specimens from newborns. Clin Chem 40:1797-1817

Chalmers RA, Bain MD, Zschocke J (2006) Riboflavin-responsive glutaryl-CoA dehydrogenase deficiency. Mol Genet Metab 29:162-172 
Christensen E (1983) Improved assay of glutaryl-CoA dehydrogenase in cultured cells and liver: application to glutaric aciduria type I. Clin Chim Acta 129:91-97

Christensen E, Ribes A, Merinero B, Zschocke J (2004) Correlation of genotype and phenotype in glutaryl-CoA dehydrogenase deficiency. J Inherit Metab Dis 27:861-868

Crombez EA, Cederbaum SD, Spector E, Chan E, Salazar D, Neidich J, Goodman S (2008) Maternal glutaric acidemia type I identified by newborn screening. Mol Genet Metab 94:132-134

Desai NK, Runge VM, Crisp DE, Crisp MB, Naul LG (2003) Magnetic resonance imaging of the brain in glutaric aciduria type I. Invest Radiol 38:489-496

Wert D (2005) Cascade screening: whose information is it anyway? Eur J Hum Genet 13:397-398

Dewey KG, Beaton G, Fjeld C, Lonnerdal B, Reeds P (1996) Protein requirements of infants and children. Eur J Clin Nutr 50:119 147

Dixon M, Leonard JV (1992) Intercurrent illness in inborn errors of intermediary metabolism. Arch Dis Child 67:1387-1391

Elster AW (2004) Value of diffusion-weighted resonance imaging for diagnosing acute striatal necrosis. J Comput Assist Tomogr 28:98-100

Forstner R, Hoffmann GF, Gassner I et al. (1999) Glutaric aciduria type I: ultrasonographic demonstration of early signs. Pediatr Radiol 29:138-143

Francis DEM, Smith I (1981) Breast-feeding regime for the treatment of infants with phenylketonuria. In: Bateman C (ed) Applied Nutrition. John Libbey, London, pp 82-83

Fu Z, Wang M, Paschke R, Rao S, Frerman FE, Kim JJP (2004) Crystal structures of human glutaryl-CoA dehydrogenase with and without an alternate substrate: structural bases of dehydrogenation and decarboxylation reactions. Biochemistry 43:9674-9684

Gallagher RC, Cowan TM, Goodman SI, Enns GM (2005) Glutaryl-CoA dehydrogenase deficiency and newborn screening: retrospective analysis of a low excretor provides further evidence that some cases may be missed. Mol Genet Metabol 86:417-420

Garcia P, Martins E, Diogo L et al. (2008) Outcome of three cases of untreated maternal glutaric aciduria type I. Eur J Pediatr 167:569-573

Gitiaux C, Roze E, Kinugawa K et al. (2008) Spectrum of movement disorders associated with glutaric aciduria type 1: a study of 16 patients. Mov Disord 23:2392-2397

Goodman SI, Markey SP, Moe PG, Miles BS, Teng CC (1975) Glutaric aciduria: a 'new' inborn error of amino acid metabolism. Biochem Med 12:12-21

Goodman SI, Stein DE, Schlesinger S et al. (1998) Glutaryl-CoA dehydrogenase mutations in glutaric acidemia (Type I): review and report of thirty novel mutations. Hum Mutat 12:141-144

Greenberg CR, Reimer D, Singal R et al. (1995) A G-to-T transversion at the +5 position of intron 1 in the glutaryl-CoA dehydrogenase gene is associated with the Island Lake variant of glutaric acidemia type I. Hum Mol Genet 4:493-495

Greenberg CR, Prasad AN, Dilling LA et al. (2002) Outcome of the three years of a DNA-based neonatal screening program for glutaric aciduria type I in Manitoba and Northwestern Ontaria, Canada. Mol Genet Metab 75:70-78

Hald JK, Nakstad PH, Skjeldal OH, Stromme P (1991) Bilateral arachnoid cysts of the temporal fossa in four children with glutaric aciduria type I. Am J Neuroradiol 12:407-409

Harting I, Neumaier-Probst E, Seitz A et al. (2009) Dynamic changes of striatal and extrastriatal abnormalities in glutaric aciduria type I. Brain 132:1764-1782

Hartley LM, Khwaja OS, Verity CM (2000) Glutaric aciduria type 1 and nonaccidental head injury. Pediatrics 107:174-175
Haworth JC, Booth FA, Chudley AE et al. (1991) Phenotypic variability in glutaric aciduria type I: report of fourteen cases in five Canadian Indian kindreds. J Pediatr 118:52-58

Hennermann JB, Roloff S, Gellerman J et al. (2009) False-positive newborn screening mimicking glutaric aciduria type I in infants with renal insufficiency. J Inherit Metab Dis. doi:10.1007/ s10545-009-9017-6

Heringer J, Boy SPN, Ensenauer R et al. (2010) Use of guidelines improves the neurological outcome in glutaric aciduria type I. Ann Neurol 68:743-752

Hoffmann GF, Trefz FK, Barth PG et al. (1991) Glutaryl-CoA dehydrogenase deficiency: a distinct encephalopathy. Pediatrics 88:1194-1203

Hoffmann GF, Athanassopoulos S, Burlina AB et al. (1996) Clinical course, early diagnosis, treatment, and prevention of disease in glutaryl-CoA dehydrogenase deficiency. Neuropediatrics 27:115123

Huner G, Baykal T, Demir F, Demirkol M (2005) Breast-feeding experience in inborn errors of metabolism other than phenylketonuria. J Inherit Metab Dis 28:457-465

Jamjoom ZA, Okamoto E, Jamjoom AH, al-Hajery O, Abu-Melha A (1995) Bilateral arachnoid cysts of the sylvian region in female siblings with glutaric aciduria type I. Report of two cases. J Neurosurg 82:1078-1081

Köhler M, Hoffmann GF (1998) Subdural haematoma in a child with glutaric aciduria type I. Pediatr Radiol 28:582

Kölker S, Garbade S, Greenberg CR et al. (2006) Natural history, outcome, and treatment efficacy in children and adults with glutaryl-CoA dehydrogenase deficiency. Pediatr Res 59:840-847

Kölker S, Garbade SF, Boy N et al. (2007a) Decline of acute encephalopathic crises in children with glutaryl-CoA dehydrogenase deficiency identified by neonatal screening in Germany. Pediatr Res 62:353-362

Kölker S, Christensen E, Leonard JV et al. (2007b) Guideline for the diagnosis and management of glutaryl-CoA dehydrogenase deficiency (glutaric aciduria type I). J Inherit Metab Dis 30:5-22

Krstulovic AM, Brown PR, Rosie DM, Champlin PB (1977) Highperformance liquid-chromatographic analysis for tryptophan in serum. Clin Chem 23:1984-1988

Külkens S, Harting I, Sauer S et al. (2005) Late-onset neurologic disease in glutaryl-CoA dehydrogenase deficiency. Neurology 64:2142-2144

Kyllerman M, Skjeldal OH, Lundberg M et al. (1994) Dystonia and dyskinesia in glutaric aciduria type I: Clinical heterogeneity and therapeutic considerations. Mov Disord 9:22-30

Kyllerman M, Skjeldal O, Christensen E et al. (2004) Long-term follow-up, neurological outcome and survival rate in 28 Nordic patients with glutaric aciduria type 1. Eur J Paediatr Neurol 8:121-129

Laich A, Neurauter G, Widner B, Fuchs D (2002) More rapid method for simultaneous measurement of trytophan and kynurenine by HPLC. Clin Chem 48:579-581

Lin SK, Hsu SG, Ho ES et al. (2002) Novel mutations and prenatal sonographic findings of glutaric aciduria (type I) in two Taiwanese families. Prenat Diagn 22:725-729

Lindner M, Kölker S, Schulze A, Christensen E, Greenberg CR, Hoffmann GF (2004) Neonatal screening for glutaryl-CoA dehydrogenase deficiency. J Inherit Metab Dis 27:851-859

Lindner M, Ho S, Fang-Hoffmann J, Hoffmann GF, Kölker S (2006) Neonatal screening for glutaric aciduria type I: strategies to proceed. J Inherit Metab Dis 29:378-382

Lipkin PH, Roe CR, Goodman SI, Batshaw ML (1988) A case of glutaric aciduria type I: effect of riboflavin and carnitine. J Pediatr 112:62-65

Lütcherath V, Waaler PE, Jellum E, Wester K (2000) Children with bilateral temporal arachnoid cysts may have glutaric aciduria type 
1 (GAT1); operation without knowing that may be harmful. Acta Neurochir (Wien) 142:1025-1030

MacDonald A, Depondt E, Evans S, Daly A, Hendriksz C, Chakrapani AA, Saudubray JM (2006) Breast feeding in IMD. J Inherit Metab Dis 29:299-303

Martinez-Lage JF, Casas C, Fernandez MA, Puche A, Rodriguez Costa T, Poza M (1994) Macrocephaly, dystonia, and bilateral temporal arachnoid cysts: glutaric aciduria type 1 . Childs Nerv Syst 10:198-203

McClelland VM, Bakalinova DB, Hendriksz C, Singh RP (2009) Glutaric aciduria type1 presenting with epilepsy. Dev Med Child Neurol 51:235-239

Mellerio C, Marignier S, Roth P et al. (2008) Prenatal cerebral ultrasound and MRI findings in glutaric aciduria type 1: a de novo case. Ultrasound Obstet Gynecol 31:712-714

Monavari AA, Naughten ER (2000) Prevention of cerebral palsy in glutaric aciduria type I by dietary management. Arch Dis Child 82:67-70

Monbaliu E, Ortibus E, Roelens F, Desloovere K, Deklerck J, Prinzie P, de Cock P, Feys H (2010) Rating scales for dystonia in cerebral palsy: reliability and validity. Dev Med Child Neurol 52:570-575

Morris AAM, Hoffmann GF, Naughten ER, Monavari AA, Collins JE, Leonard JV (1999) Glutaric aciduria and suspected child abuse. Arch Dis Child 80:404-405

Morton DH, Bennett MJ, Seargeant LE, Nichter CA, Kelley RI (1991) A common cause of episodic encephalopathy an spastic paralysis in the Amish of Lancaster County, Pennsylvania. Am J Med Genet 41:89-95

Mühlhausen C, Hoffmann GF, Strauss KA et al. (2004) Maintenance treatment of glutaryl-CoA dehydrogenase deficiency. J Inherit Metab Dis 27:885-892

Müller E, Kölker S (2004) Reduction of lysine intake while avoiding malnutrition - major goals and major problems in dietary treatment of glutaryl-CoA dehydrogenase deficiency. J Inherit Metab Dis 27:903-910

Napolitano N, Wiley V, Pitt JJ (2004) Pseudo-glutarylcarnitinaemia in medium-chain acyl-CoA dehydrogenase deficiency detected by tandem mass spectrometry newborn screening. J Inherit Metab Dis $27: 465-471$

Nasser M, Javaheri H, Fedorowicz Z, Noorani Z (2009) Carnitine supplementation for inborn errors of metabolism. Cochrane Database Syst Rev 2:CD006659

Naughten ER, Mayne PD, Monavari AA, Goodman SI, Sulaiman G, Croke DT (2004) Glutaric Aciduria type I, Outcome in the Republic of Ireland. J Inherit Metab Dis 27:917-920

Neumaier-Probst E, Harting I, Seitz A, Ding C, Kölker S (2004) Neuroradiological findings in glutaric aciduria type I (glutaryl-CoA dehydrogenase deficiency). J Inherit Metab Dis 27:869-876

Oguz KK, Ozturk A, Cila A (2005) Diffusion-weighted MR imaging and MR spectroscopy in glutaric aciduria type I. Neuroradiology 47:229-234

Pollitt RJ, Green A, McCabe CJ et al. (1997) Neonatal screening for inborn errors of metabolism: cost, yield and outcome. Health Technol Assess 1:1-202

Prietsch V, Lindner M, Zschocke J, Nyhan WL, Hoffmann GF (2002) Emergency management of inherited metabolic diseases. J Inherit Metab Dis 25:531-546

Rakocevic G, Lyons KE, Wilkinson SB, Overman JW, Pahwa R (2004) Bilateral pallidotomy for severe dystonia in an 18month-old child with glutaric aciduria. Stereotact Funct Neurosurg 82:80-83

Rice J, Waugh MC (2009) Pilot study on trihexiphenidyl in the treatment of dystonia in children with cerebral palsy. J Child Neurol 24:176-182

Sanger TD, Bastian A, Brunstrom J et al. (2007) Prospective open-label clinical trial of trihexiphenidyl in children with secondary dystonia due to cerebral palsy. J Child Neurol 22:530-537
Sauer SW, Opp S, Hoffmann GF, Koeller DM, Okun JG, Kölker S (2010) Therapeutic modulation of cerebral L-lysine metabolism in a mouse model for glutaric aciduria type I. Brain. doi:10.1093/brain/awq269

Seccombe DW, James L, Booth F (1986) L-Carnitine treatment in glutaric aciduria type I. Neurology 36:264-267

Shigematsu Y, Hata I, Tanaka Y, Tajima G, Sakura N, Naito E, Yorifuri T (2005) Stable-isotope dilution gas chromatography-mass spectrometric measurement of 3-hydroxyglutaric acid, glutaric acid and related metabolites in body fluids of patients with glutaric aciduria type 1 found in newborn screening. J Chromatogr B Analyt Technol Biomed Life Sci 823:7-12

Smith WE, Millington DS, Koeberl DD, Lesser PS (2001) Glutaric academia, type I, missed by newborn screening in an infant with dystonia following promethazine administration. Pediatrics 107:1184-1187

Strauss KA, Puffenberger EG, Robinson DL, Morton DH (2003) Type I glutaric aciduria, part 1: natural history of 77 patients. Am J Med Genet 121C:38-52

Strauss KA, Lazovic J, Wintermark M, Morton DH (2007) Multimodal imaging of striatal degeneration in Amish patients with glutaryl-CoA dehydrogenase deficiency. Brain 130:1905-1920

Thomason MJ, Lord J, Bain MD, Chalmers RA, Littlejohns P, Addison GM, Wilcox AH, Seymour CA (1998) A systematic review of evidence for the appropriateness of neonatal screening programmes for inborn errors of metabolism. J Public Health Med 20:331-343

Tortorelli S, Hahn SH, Cowan TM, Brewster TG, Rinaldo P, Matern D (2005) The urinary excretion of glutarylcarnitine is an informative tool in the biochemical diagnosis of glutaric aciduria type I. Mol Genet Metab 84:137-143

Treacy EP, Lee-Chong A, Roche G, Lynch B, Ryan S, Goodman SI (2003) Profound neurological presentation resulting from homozygosity for a mild glutaryl-CoA dehydrogenase mutation with a minimal biochemical phenotype. J Inherit Metab Dis 26:72-74

Twomey EL, Naughten ER, Donoghue VB, Ryan S (2003) Neuroimaging findings in glutaric aciduria type I. Pediatr Radiol $33: 823-830$

Van Rijn M, Bekhof J, Dijkstra T, Smit PG, Moddermam P, van Spronsen FJ (2003) A different approach to breast-feeding of the infant with phenylketonuria. Eur J Pediatr 162:323-326

Walter JH (2003) L-Carnitine in inborn errors of metabolism: What is the evidence? J Inherit Metab Dis 26:181-188

Walter JH, Patterson A, Till J et al. (2009) Bloodspot acylcarnitine and amino acid analysis in cord blood samples: efficacy and reference data from a large cohort study. J Inherit Metab Dis 32:35-101

Watson MS, Mann MY, Lloyd-Puryear MA et al. (2006) Newborn screening: toward a uniform screening panel and system executive summary. Pediatrics 117:S315-S319

Wilcken B, Wiley V, Hammond J, K1 C (2003) Screening newborns for inborn errors of metabolism by tandem mass spectrometry. $\mathrm{N}$ Engl J Med 348:2304-2312

Woelfle J, Kreft B, Emons D, Haverkamp F (1996) Subdural hematoma and glutaric aciduria type I. Pediatr Radiol 26:779-781

World Health Organization (2007) Protein and amino acid requirements in human nutrition. Report of a joint WHO/FAO/UNU expert consultation. WHO Technical Report Series 935. World Health Organization, Geneva

Yannicelli S, Rohr F, Warman FL (1994) Nutrition support for glutaric acidemia type I. J Am Diet Assoc 94:183-191

Zinnanti WJ, Lazovic J, Housman C, LaNoue K, O'Callaghan JP, Simpson I, Woontner M, Goodman SI, Connor JR, Jacobs RE, Cheng KC (2007) Mechanism of age-dependent susceptibility and novel treatment strategy in glutaric acidemia type I. J Clin Invest 117:3258-3270

Zschocke J, Quak E, Guldberg P, Hoffmann GF (2000) Mutation analysis in glutaric aciduria type I. J Med Genet 37:177-181 